\title{
Electromagnetic Information Transfer (EMIT) by Ultra High Diluted (UHD) solutions: the suggestive hypothesis of an epigenetic action
}

\author{
Francesco Borghini ${ }^{1}$, Giovanni Dinelli², Ilaria Marotti², Grazia Trebbi², \\ Giovanni Borghini ${ }^{3}$, Lucietta Betti ${ }^{2}$
}

\author{
1Department of Medical Therapy, University of Chieti, Chieti, Italy \\ 2Department of Agroenvironmental Sciences and Technologies, University of Bologna, Italy \\ ${ }^{3}$ Stella Maris Center, Roma, Italy
}

\begin{abstract}
The aim of this work is to confirm the theoretical possibility of an epigenetic mechanism shared between EMIT and UHD. The presentation will be divided in three sections:

1. Water aggregates with an electric dipole moment (UHD succussed solutions) as mediators of weak specific bioelectromagnetic signals on target stem cells.

Recent experimental works confirm the developing concept of water mediated Electromagnetic Information Transfer (EMIT) of specific molecular signals, picked up from the source biological effector, on target stem cells with evident effect on their proliferation [1]. Similar Electromagnetic (EM) emission and consequences are also reported by the scientific literature on rotational excited aggregates with an electric dipole moment, created in polar liquids by Ultra High Diluted (UHD) or High Diluted (HD) succussed solutions. These aggregates are composed of solvent molecules only or a combination of these and solute particles [2].
\end{abstract}

\section{DNA mediated physiopathological effects of ELF EMFs}

In detail, according to the International Agency for Research on Cancer (IARC), the extremely low-frequency (ELF) electromagnetic fields (EMFs) are classified as "possible carcinogenic" based on their effects [3-5], although most scientists agree that they are too weak to kill cells or to cause mutations and thus initiate cancer. Besides the prevailing paradigm of the environmentally-induced acute and chronic diseases involving either cell killing (cytotoxicity) or gene/chromosome mutations (genotoxicity), many studies concerning the biological and health consequences of ELF-EM exposure report that alteration of the expression of genetic information at the transcriptional, translational, or posttranslational levels has the potential to contribute to various diseases.

\section{Epigenetic mechanism shared between EMIT and UHDs}

The latter referred mechanism, denoted as "epigenetic" (that affects gene expression rather than gene structure), is characterized by threshold-like action, multiple biochemical pathways and it needs chronic regular exposures to be effective [6]. 
Epigenetic factors affect one of four potential cell states, namely alteration of cell proliferation, cell differentiation, programmed cell death (apoptosis) or adaptive responses of differentiated cells, and probably they act as co-inductors of DNA damage rather than as a genotoxic agents per se. At the present time, studies on genomic and functional genetic are identifying many genes and gene variants that potentially modulate the fundamental molecular mechanisms underpinning both physiological and pathological processes.

Keywords: Electromagnetic Information Transfer, Ultra High Dilutions, Epigenetic, Extremely lowfrequency electromagnetic fields

\section{References}

[1] Foletti, A., Ledda, M., D'Emilia, E., Grimaldi, S., and Lisi, A. Experimental finding on the electromagnetic information transfer of specific molecular signals mediated through the aqueous system on two human cellular models. J. Altern. Complement. Med. 2012; 18, 258-261.

[2] Yinnon, T.A., and Yinnon, C.A. Electric dipole aggregates in very dilute polar liquids: theory and experimental evidence. IJMPB 2011; 25, 3707-3743.

[3] Wolf FI et al. 50-Hz extremely low frequency electromagnetic fields enhance cell proliferation and DNA damage: possible involvement of a redox mechanism. Biochim Biophys Acta. 2005; 22;1743(1-2):120-129.

[4] Simkó M. Cell type specific redox status is responsible for diverse electromagnetic field effects. Curr Med Chem. 2007; 14(10):1141-1152.

[5] Ruiz-Gómez MJ, Martínez-Morillo M. Electromagnetic fields and the induction of DNA strand breaks. Electromagn Biol Med. 2009; 28(2):201-214.

[6] Trosko JE. Human health consequences of environmentally-modulated gene expression: potential roles of ELF-EMF induced epigenetic versus mutagenic mechanisms of disease. Bioelectromagnetics, 2000;21(5):402406.

(c)) EY-NC-ND Licensed to GIRI

Support: authors declare that this study received no funding

Conflict of interest: authors declare there is no conflict of interest

Received: 01 June 2012; Revised: 10 August 2012; Published: 30 September 2012.

Correspondence author: Francesco Borghini, Department of Medical Therapy, University of Chieti, Chieti, Italy; website: http://www.med.unich.it/ frabor@tiscali.it.

How to cite this article: Borghini F, Dinelli G, Marotti I, Trebbi G, Borghini G, Betti L. Electromagnetic Information Transfer (EMIT) by Ultra High Diluted (UHD) solutions: the suggestive hypothesis of an epigenetic action. Int J High Dilution Res [online]. 2012 [cited YYYY Month dd]; 11(40):113-114. Proceedings of the XXVI GIRI Symposium; 2012 Sep 20-22; Florence (Italy). GIRI; 2012; Available from: http://www.feg.unesp.br/ ojs/index.php/ijhdr/article/view/582/591 